REVISTA DE ESTUDOS EM ARTES CÊNICAS

E-ISSN 2358.6958

\title{
Em torno dos Viewpoints e a partir da SITI-Company
}

Entrevista com Barney O'Hanlon concedida a Tiago Mora Porteiro

\section{Para citar este artigo:}

O'HANLON, Barney; PORTEIRO, Tiago Mora. Em torno dos Viewpoints e a partir da SITI-Company. [Entrevista concedida a Tiago Mora Porteiro]. Urdimento - Revista de Estudos em Artes Cênicas, Florianópolis, v. 3, n. 42, p.1-24, dez. 2021.

doi DOI: http:/dx.doi.org/10.5965/1414573103422021e0502 


\title{
Em torno dos Viewpoints e a partir da SITI-Company
}

Entrevista com Barney O’Hanlon concedida a Tiago Mora Porteiro'

\begin{abstract}
Resumo
Nesta entrevista, realizada no espaço de trabalho da SITI-Company (NY) em maio de 2017, no final do III Conservatory SITI-Company, em que o entrevistador participou, Barney O'Hanlon, membro da SITI-Company desde 1994, partilha uma biografia crítica sobre o seu próprio percurso, reflete sobre a sua prática pessoal através dos sistemas de treinamento e composição Suzuki e Viewpoints, ao mesmo tempo que analisa dimensões estruturantes e modos de funcionamento da companhia da qual faz parte. Salienta-se, neste contexto, o facto de o entrevistado se apresentar, no domínio dos Viewpoints, como o membro da SITI que mais articula a abordagem de Anne Bogart com a de Mary Overlie, a artista que esteve na origem dos Viewpoints e com a qual trabalhou e conviveu.
\end{abstract}

Palavras-chave: SITI-Company. SITI-Conservatory. Viewpoints. Suzuki. Artes performativas.

\section{Around Viewpoints from SITI-Company: Interview with Barney O'Hanlon by Tiago Porteiro}

\begin{abstract}
In this interview, carried out at the SITI-Company workspace (NY), in May 2017, at the end of the III SITI-Company Conservatory, in which the interviewer participated, Barney O'Hanlon, member from SITI-Company since 1994, shares a critical biography about his own path, reflects on his personal practice through the Suzuki and Viewpoints training and composition systems, while analyzing structural dimensions and operating modes of this company of which he is a part. In this context, it stands out the fact that the interviewee presents himself, in the Viewpoints domain, as the member of SITI-Company that most articulates Anne Bogart's approach with that of Mary Overlie, the artist who was in the origin of Viewpoints and with whom he worked and developed a close relationship.
\end{abstract}

Keywords: SITI-Company. SITI-Conservatory. Viewpoints. Suzuki. Performing arts. 


\section{Alrededor de Viewpoints y desde SITI-Company}

\section{Resumen}

En esta entrevista, realizada en el espacio de trabajo de SITI-Company (NY), en mayo de 2017, al finalizar el III SITI-Company Conservatory, en el que participó el entrevistador, Barney O'Hanlon, miembro de la SITI-Company desde 1994, comparte una biografía crítica sobre su propio camino, reflexiona sobre su práctica personal a través de los sistemas de formación y composición suzuki y Viewpoints, mientras analiza las dimensiones estructurales y modos de funcionamiento de la compañía de la que forma parte. En este contexto, el entrevistado se presenta, en el dominio de Viewpoints, como el miembro de SITI-Company que más articula el enfoque de Anne Bogart con el de Mary Overlie, la artista que estuvo en el origen de Viewpoints y con quien trabajó y convivió.

Palabras clave: SITI-Company. SITI-Conservatory. Viewpoints. Suzuki. Artes escénicas. 
Participei no programa de formação e intercâmbio artístico promovido pela companhia americana de artes performativas SITI - III edição do SITI-Conservatory (NY-EUA, outubro 2016 - maio 2017) - enquanto artista mas também enquanto pedagogo e investigador. Para desenvolver uma futura investigação decidi, no final do programa, entrevistar a grande maioria daqueles que mais diretamente orientaram as sessões de trabalho ao longo dos oito meses ${ }^{2}$, mas também alguns dos que foram convidados para dirigir intervenções mais curtas e específicas, como ainda algumas das pessoas que estavam envolvidas na gestão e na coordenação desse mesmo programa. Recolhi, além disso, depoimentos sobre a experiência SITI-Conservatory junto dos artistas-alunos participantes.

Esta atividade de recolha de testemunhos tinha como intuito ser a base na qual assentaria a minha reflexão crítica futura sobre o SITI-Conservatory. A verdade é que, passados mais de quatro anos, grande parte desse trabalho está ainda por realizar, apesar de um artigo, onde desenvolvo uma reflexão em tom pessoal sobre essa minha experiência, ter sido já produzido³.

As entrevistas realizadas aos artistas-pedagogos foram, antecipadamente, preparadas num guião onde predominavam tópicos que, de alguma forma, estiveram em jogo no programa do Conservatory - pertinência no seio da atividade da companhia, estrutura e desenho do programa, funcionamento e questões levantadas no decurso da ação, bem como aspetos técnicos de cada uma das áreas de trabalho (entre outras, Viewpoints, Suzuki, Composição, Movimento, Voz, Estudo de cenas); e ainda, paralelamente, os detalhes do percurso de cada um dos envolvidos, que me interessou conhecer no sentido de melhor compreender e questionar as especificidades pedagógicas que a cada um fui reconhecendo no decurso do programa. As questões delineadas a priori não foram senão linhas de orientação, pelo que estamos, portanto, perante entrevistas semidirigidas e que foram, todas elas, gravadas em formato áudio para posterior transcrição, tradução e análise. Na realidade, casos houve em que o formato entrevista deslizou

\footnotetext{
2 Em particular, para além de Barney O’Hanlon: Akiko Aizawa, Gian- Murray Gianino, Leon Ingulsrud, Ellen Lauren, Stephen Duff Webber. E com uma participação mais pontual: Anne Bogard, Will Bond e Kelly Maurer Informação mais detalhada sobre a equipa da SITI-company pode ser encontrada em https://siti.org/about/company/
}

${ }^{3}$ Porteiro, 2018. 
essencialmente para o tom conversacional e dialógico.

O dossier que, em bom momento, esta revista lança foi o estímulo que me faltava para ativar esse manancial de informações que se encontram à espera do momento mais oportuno para se revelarem publicamente.

A decisão de propor, a apresentação da conversa travada com o artistapedagogo Barney O'Hanlon, que passou a integrar a SITI-Company dois anos após a sua fundação, prende-se com o facto de ele ser o que, no seio do grupo, mais faz a 'ponte' entre a abordagem Viewpoints proposta por Anne Bogart ${ }^{4}$ e a de Mary Overlie ${ }^{5}$, artista que esteve na origem desta perspetiva. Esta opção é também o meu singelo contributo para que a sua memória não se apague, particularmente certa de um ano depois em que nos deixou ${ }^{6}$. Depois de terminar o Conservatory, tive necessidade de conhecer os fundamentos iniciais dos Viewpoints, e foi por isso que, passados dois meses, participei numa formação orientada por Overlie e, um ano depois, num dos últimos laboratórios que terá orientado?. E esses dois encontros foram, na verdade, uma revelação na medida em que me permitiu perceber o quão os Viewpoints se fundam numa dimensão mais preceptiva e contemplativa do que materialista e operativa. Em síntese, Mary propõe: "ouve e olha o que já existe em vez de tentar manipular os materiais em algo que pareça arte ou teatro ou dança. Simplesmente estar lá no presente, estar disponível e curioso" (Overly, 2016, X) ${ }^{8}$.

Resta-me acrescentar que esta entrevistas foi realizada em língua inglesa e que, na sua tradução para português, por mim realizada, houve, por vezes, um livre

${ }^{4}$ Anne Bogart, americana, mulher de constantes intercâmbios culturais, começou a afirmar a sua visão singular do teatro e da performance no início dos anos 80 e numa NY efervescente em dinâmicas artísticas contemporâneas.

${ }^{5} \mathrm{O}$ trabalho de Mary Overlie, artista Americana (Montana) e autora da abordagem Viewpoints, inscrevese no movimento da dança pós-moderna americana. A sua inovadora ação, artística e pedagógica, situase no território dos cruzamentos artísticos - dança, performance, teatro, artes visuais, improvisação. Antes de dedicar-se a título individual ao trabalho de aprofundamento e divulgação da sua própria abordagem, foi interprete de reconhecidas companhias de dança e cofundadora de vários projetos de referência, associativos e de investigação, no domínio experimental das artes performativas.

${ }^{6}$ Junho de 2020

7 Oficina "A Matriz Criativa dos seis Viewpoints", com Mary Overlie. Org. Vértico. Centro de Danza Canal (Madrid). 24-26/06 - 2017; Laboratório "Seis Viewpoints", com Mary Overlie, Wendell Beavers e Erika Berland. Org. Vértico. Residência na Casa del Pino em Hondón de las Nieves, Alicante, Espanha. 19-26/07 - 2019.

${ }^{8}$ Mary Overly. Standing in Space. The six Viwpoints Theory \& Pratice ». Montana. Fallon Presse, 2016. 
entendimento para encontrar os termos que melhor expressassem o que entendia do modo de enunciar dos entrevistados, como neste caso, especificamente, do Barney. Aqui agradeço também a sua disponibilidade para conceder-me esta conversa, como ainda a sua disponibilidade para clarificar, no presente, aspetos que me haviam deixado algumas dúvidas. E no final, justa-se ainda duas questões que the coloquei atualmente.

Figura 1 - Barney O’Hanlon

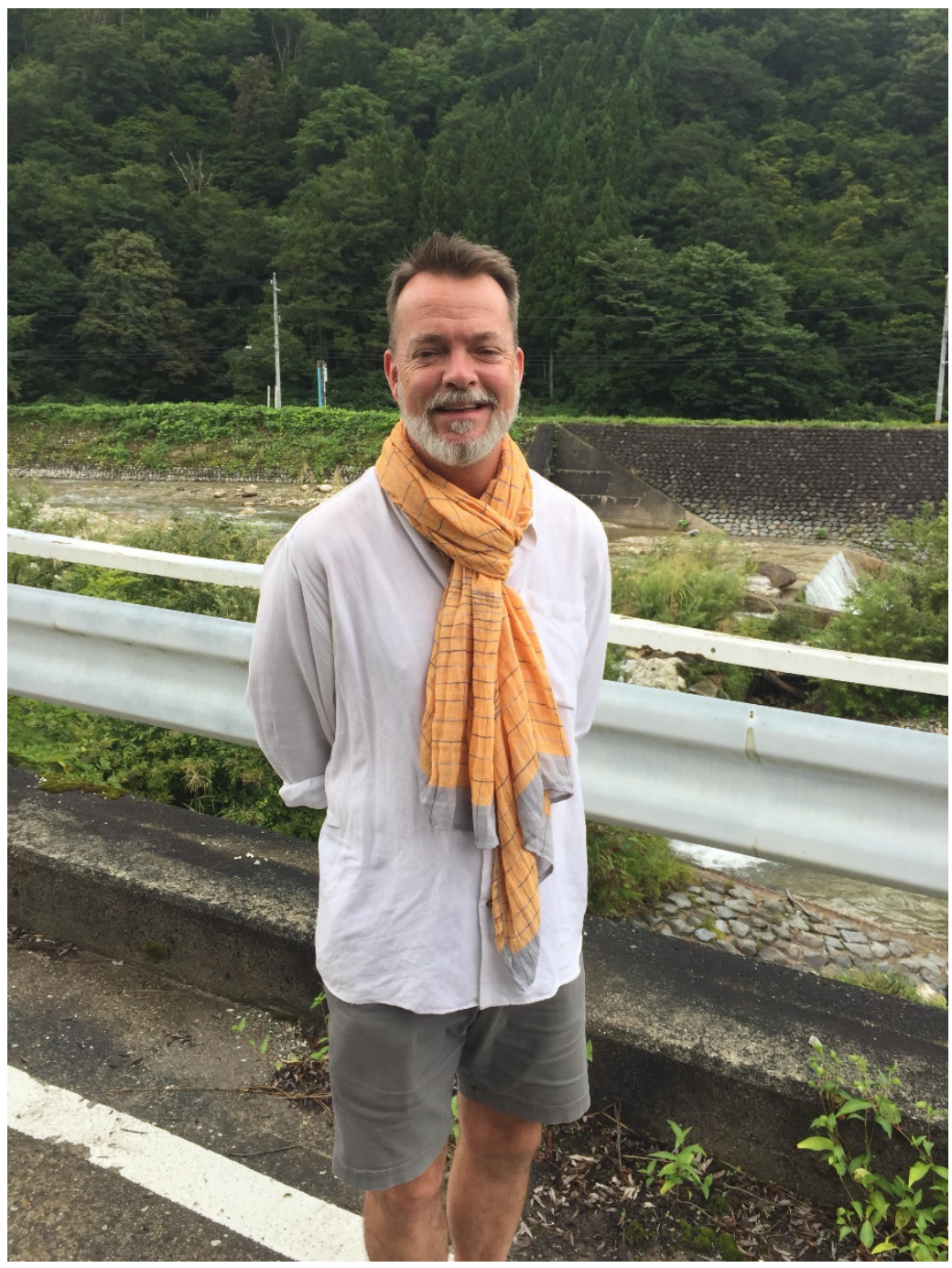

Fotografia tirada em Togamura, Japão, quando a SITI atuou no teatro Olympics 
Poderás explicitar o teu percurso formativo no âmbito das artes performativas, em particular a tua relação com Mary Overlie ${ }^{9}$ e a SITI Company?

Em 1984, quando iniciava a minha formação na licenciatura em Artes Performativas - Experimental Theatre Wing ${ }^{10}$, na New York University (NYU), Anne Bogart ${ }^{11}$ foi convidada para dirigir um projeto de criação. Encenou O Despertar da Primavera como se de um musical rock se tratasse. Fiquei deslumbrado quando assisti à apresentação final do projeto, pois nunca tinha visto nada que me entusiasmasse tanto!

Dois anos depois, Anne foi de novo convidada para dirigir um projeto na NYU. Apresentei-me à audição e ela escolheu-me. Foi aí que tive o meu primeiro contacto com os Viewpoints, pois era parte integrante do training e, de algum modo, também da metodologia da criação. Wendell Beavers ${ }^{12}$, que tu conheces e que, naquela altura, formava um casal com Mary Overlie, também integrava a equipa de Anne. Havia ainda outros artistas envolvidos, cada um deles responsável por uma área do projeto. Todos trabalhavam sob a orientação da Anne.

Participar naquele projeto dirigido por Anne B. mudou a minha vida! Até porque, antes de entrar na universidade, não conhecia muito do que se estava a fazer no âmbito do teatro experimental. De um momento para o outro, descobri um novo mundo, ainda que, antes de entrar na universidade, já tivesse tido aulas de movimento com um professor que tinha trabalhado com Meredith Monk ${ }^{13}$ -

${ }_{9}^{9}$ Para conhecer mais em detalhe o percurso de Mary Overlie ver: https://sixviewpoints.com/biography

10 Ver informação em: https://tisch.nyu.edu/drama/about/studios/experimental-theatre-wing. Numa informação que me prestou posteriormente detalhou o seguinte: Entrei no BFA da NYU em 1984. No 10 ano no Conservatório foi desenvolvido na escola de Stella Adler; no 2 o ano, no Michael Chekhov Studio. E finalmente no 3으 e no 4ㅇa ano no Experimental Theatre Wing.

11 Informação mais detalhada sobre a equipa da SITI-company pode ser encontrada em https://siti.org/about/company/

12 Wendell Beavers, americano, desenvolve o seu trabalho artístico enquanto bailarino, performer e pedagogo. É um dos artistas que mais colaborou de perto com Mary Overlie. No âmbito da pedagogia, destaca-se o facto de ter estado na origem de vários programas experimentais de formação artística, entre outros, ETW na NYU e MFA Theatre, na Naropa University. O estudo que desenvolve com Bonnie Bainbridge Cohen abre-lhe uma outra área de atuação, o Body Ming Centering®, técnica da qual é atualmente professor. Mais informações podem ser encontradas em: https://movementresearch.org/people/wendell-beavers.

${ }^{13}$ Meredith Monk é uma das mais reconhecidas e singulares artistas Americanas das últimas décadas no 
Paul Langland ${ }^{14}$. Foi ele que me sugeriu a formação na NYU.

Quando terminei o curso na NYU, continuei a minha descoberta sobre o teatro contemporâneo que, naquela altura, se estava a fazer em NY, especialmente tudo o que se passava no Movement Research ${ }^{15}$, e nomeadamente em torno da Contact Improvisation. E continuei igualmente a seguir o trabalho que Anne desenvolvia. Depois de ter participado em algumas das formações que ela orientava, Anne convidou-me a integrar alguns dos seus projetos de criação. E, pouco tempo depois de ter criado a SITI'16, convida-me, finalmente, para integrar a companhia [1994]. Aí chegado, para além de fazer parte dos espetáculos enquanto performer, comecei, paralelamente, a ensinar.

Porque a pedagogia sempre esteve associada ao projeto da companhia?

Sim.

O trabalho da Anne Bogart, da SITI, interessou-te também porque, na sua poética, essa relação com a corporalidade e com o movimento está presente - dimensões essas que tinhas também tu próprio interesse em desenvolver e explorar?

O meu crescimento artístico foi feito com a Anne Bogart. O meu sonho foi sempre o de fazer parte de uma companhia durante um período mais longo de tempo e de poder desenvolver um repertório no seio de uma equipa que trabalhava em conjunto. Nunca quis ter um agente e fazer teatro comercial. É

âmbito das artes performativas. Compositora e interprete, o seu trabalho experimental e inovador desenvolve-se particularmente em torno das potencialidades sonoras da voz e onde a música, o teatro e artes visuais se cruzam. Mais informações podem ser encontradas em: https://www.meredithmonk.org/

${ }^{14} \mathrm{O}$ artista pertenceu à Mary Dance Company na década de 70. Paul e Mary trabalharam juntos durante várias décadas.

15 Movement Research - School for Movement Research \& Construction - é um dos mais icónicos e proeminentes laboratórios de criação e investigação no âmbito da dança pós-moderna, movimento e performance, criado em 1978 em NY. Nas aulas, workshops, residências de criação e apresentação de espetáculos há um especial enfoque na análise da relação entre artes, cultura, economia e política. Mais informações podem ser encontrada em: https://movementresearch.org/about

${ }^{16}$ A companhia foi fundada em 1992 e liderada artisticamente por Tadashi Suzuki (1939-) e Anne Bogart (1951) tendo, cada um deles, percursos já anteriormente firmados. 
verdade que antes de entrar na SITI eu fazia parte de uma companhia que trabalha na linha do divising e da dança-teatro. Mas sim, a poética da Anne, onde a corporalidade e o treino são elementos centrais, fez-me efetivamente ter interesse pelo seu trabalho.

\section{De forma genérica, como é que nessa altura a companhia funcionava?}

Posso fazer-te um desenho muito geral do modo como, nos primeiros anos, funcionávamos.

Saliento, em primeiro lugar, o Skidemor, pois era uma atividade formativa e de investigação - um curso de verão - recorrente na calendarização anual da companhia. Curso de verão com a duração aproximada de cinco semanas que até hoje tem sido organizado e que reúne todos os anos cerca de 60 artistas de todo o mundo. Era um período delimitado no tempo mas muito intenso, pois vivíamos juntos - comíamos, bebíamos, conversávamos, discutíamos e refletíamos muito, ao mesmo tempo que orientávamos sessões de trabalho (treino e composição) e, por vezes, ainda ensaiávamos e/ou apresentávamos projetos de criação ${ }^{17}$. No resto do ano havia os momentos em que estávamos envolvidos em projetos de criação e outros onde dirigíamos workshops e treinávamos. No momento das produções normalmente treinávamos pela manhã, à tarde cada um tinha ocupações diferentes e depois à noite ensaiávamos. Mas nem sempre todos os membros da companhia integravam o elenco dos projetos e, se assim fosse, poderias envolverte noutros projetos e com outros artistas e grupos.

A Anne, dependendo da altura, para além dos da SITI, desenvolvia também outros projetos. A Anne sempre teve vários compromissos ao mesmo tempo.

Podemos dizer que, no calendário anual, Skidemor era o momento mais previsível?

Esse foi sempre um momento 'sagrado', pois permitia-nos estarmos todos 
concentrados e empenhados em partilhar o nosso trabalho com artistas que vinham de diferentes partes do mundo. Posso mesmo referir que juntarmo-nos para disseminar o nosso trabalho torna-se um momento, de certa forma, 'espiritual' e que nos permite ainda sentir o 'pulso' da companhia.

Skidemor não era também o momento em que a SITI Company se encontrava com a SCOT Company of Toga ${ }^{18}$ e onde trabalhavam juntos?

Desde que eu integrei a SITI não foram assim tantas as vezes em que, no Skidemor, esse encontro entre companhias aconteceu. É verdade que em 92 e 93 as duas companhias encontraram-se ali dois anos de seguida, mas depois os encontros foram bem mais espaçados no tempo. Por várias vezes também nos encontrámos no Japão, em Toga.

Aproveitando esta oportunidade: essa relação entre técnicas referidas como 'orientais' e 'ocidentais', que a Anne procurou criar com o artista Tadashi Suzuki, faz-me lembrar o projeto da Ariane Mnouchkine com o seu Théâtre du Soleil19. Sei que Anne Bogart passou algum tempo com ela em França, mas esse encontro surge pouco explicitado quando observamos a sua biografia. Conhecendo alguma coisa do trabalho desenvolvido pela Ariane segui, por exemplo, algumas formações na ARTA ${ }^{20}$, com artistas que faziam parte do Théatre du Soleil -, considero que o que Anne Bogart fez nos USA terá mais similitudes do que possa parecer com o projeto desenvolvido pela Ariane. O que te parece?

Se Anne não tivesse encontrado Mnouchkine, ela não teria realizado o mesmo projeto que fez aqui nos EUA ao criar a SITI.

Voltando um pouco atrás. Fazer parte da SITI implicava o compromisso de

18 Suzuki Company of Toga, liderada artisticamente por Tadashi Suzuki (1939-). Ver: http://www.scotsuzukicompany.com

${ }^{19}$ O nome da encenadora Ariane M. está intimamente associado ao Théâtre du Soleil (Paris), criado em 1970, e que continua a ser um dos projetos mais inovadores e incontornáveis do teatro mundial. Caracterizador do projeto é o facto do trabalho se desenvolver em torno de um grupo composto por atores e atrizes de diferentes origens culturais e da sua linguagem cénica se desenhar em torno da revisitação e diálogo com tradições culturais e artísticas de diferentes continentes. Mais informações podem ser encontradas em: https://www.theatre-du-soleil.fr/fr/notre-theatre/histoire-et-sources.

${ }^{20}$ Association de Recherche des Traditions de l'Acteur - https://artacartoucherie.com/ 
Sim, tanto Suzuki como Viewpoints. Desde o início que a companhia abria essas sessões de treino a outros artistas. Era também, para nós, um espaço para nos exercitarmos enquanto pedagogos.

\begin{abstract}
Podemos dizer, portanto, que era nessas sessões de prática, e onde outros artistas participavam, que os membros da companhia treinavam? Essa 'mistura' não seria também um modo que a companhia encontrou para angariar fundos para pagar aos seus artistas permanentes?
\end{abstract}

Exatamente.

Tinhas um salário fixo durante todo o ano, enquanto membro da SITI?

Quando integrei a companhia era 'contratado', mas nem sempre a tempo inteiro. Progressivamente, a companhia torna-se financeiramente mais sustentada, pois passámos a ter mais projetos de criação e começámos também a fazer muito mais tournées com esses mesmos projetos, tanto dentro do país como internacionalmente.

Essa forma 'aberta' de funcionar parece-me uma estratégia muito astuta, para além das questões de gestão económica, permite ainda um questionamento constante dos seus membros, ou seja, essa estratégia pode funcionar como um 'fermento' capaz de renovar os hábitos que, forçosamente, tendem a instalar-se quando as mesmas pessoas trabalham juntas por um longo período de tempo. De certa forma, o Skidemor teria também, de algum modo, essa função de renovação, pois naquele período viviam juntos fora do contexto habitual de cada um em NY.

$\mathrm{Na}$ verdade, quanto te encontras em Skidemor estás muito mais concentrado, pois não existem tantas distrações como quando trabalhas no coração da cidade que é NY. É um tempo muito especial e intenso. 

encontraste Mary Overlie.

Depois de integrar a SITI, mais ou menos passados seis anos, comecei a aperceber-me de que as improvisações que fazíamos caíam sempre nos mesmos mecanismos e, por consequência, os resultados eram quase sempre idênticos. Na nossa ação pedagógica de conduzir as improvisações encontrávamos, igualmente, muitos hábitos que se repetiam. "Haverá qualquer coisa de errado no que estamos a fazer..." - comecei eu a pensar.

Por essa mesma altura, Mary Overlie começava a reclamar a filiação dos Viewpoints, que a SITI Company tinha, de algum modo, passado a representar. Mary Overlie e Wendell Beavers decidem propor um laboratório de experimentação/formação de Viewpoints durante seis boas semanas. Eu e o Will Bond ${ }^{21}$ fomos convidados a participar enquanto professores, mas também enquanto intervenientes. Anne também foi convidada a participar.

\section{Era uma situação um pouco bizarra, não? Em determinado momento Anne cruzou-se com o trabalho de Overlie e depois, de algum modo, apropriou-se dessa abordagem. Passados alguns anos, talvez quando a SITI Company começou a ter algum reconhecimento, nomeadamente por causa dos Viewpoints, Mary, reclamando a 'maternidade' dos Viewpoints, convida Anne para um momento de questionamento e formação. Como se estivesse a propor que Anne fizesse como que um retorno à 'fonte'?}

Nessa altura Mary sempre quis que a Anne estudasse com ela, e esse foi o motivo do seu convite, mas isso nunca aconteceu.

Nos anos 80, quando tomei contacto com a proposta de Anne, trabalhávamos a partir de seis Viewpoints. Mas depois ela foi acrescentando outros Viewpoints. E foi já nesse contexto que comecei a notar que havia qualquer coisa nas improvisações que não estava a funcionar completamente, que não nos conduzia

${ }^{21}$ Will Bond, é um dos artistas fundadores da SITI-Company e um dos mais reconhecidos pelo seu trabalho enquanto ator e performer. Para além dos trabalhos com a SITI-Company destaca-se os projetos que desenvolveu como perfomer na New York City Opera e com a Bill T Jones/Arnie Zane Dance Company. Mais informações podem ser encontradas em: https://theater.skidmore.edu/2019/05/faculty-spotlight-willbond/; https://siti.org/about/company/ 
a uma 'liberdade'.

O laboratório em que participei, com Mary e Wendell, permitiu-me descobrir os fundamentos dos Viewpoints e, ao mesmo tempo, outras dimensões que estão como que inscritas na génese dessa abordagem. A partir desse encontro, o modo como desenvolvia e como ensinava os Viewpoints começou a alterar-se. Trouxe para o interior da companhia esse conhecimento e essa necessidade de autoquestionamento. Os meus colegas começaram a aperceber-se, tal como eu próprio, de que por detrás dos Viewpoints havia uma longa história de reflexão e que se poderia desenvolver um trabalho muito mais em 'profundidade'. Aquelas seis semanas de trabalho deixaram laços, pois, a partir daí, continuei a acompanhar o trabalho de Mary Overlie. Entre nós criaram-se cumplicidades e mesmo uma amizade. Faço parte dos artistas de segunda ou terceira geração que trabalharam com a Mary22.

Depois daquele período mais específico onde trabalhaste de forma mais intensa com Mary Overlie, houve especificamente outros momentos em que voltaste a trabalhar com ela?

Trabalho propriamente prático e durante um período de tempo significativo nem por isso. Mas continuei a conviver com ela, muitas vezes jantámos juntos e, ao longo dos anos, continuámos a conversar e a discutir sobre o trabalho.

\begin{abstract}
Gostaria aqui de partilhar uma sensação que foi sendo construída ao longo destes oito meses do Conservatory: sinto, como que 'no ar', que entre Mary e Anne existem aspetos que não foram bem resolvidos, digamos assim. Esta conclusão a que chego nasce a partir de pequenos indícios, como conversas e/ou comentários que foram surgindo ao longo das sessões. No momento em que o livro de Mary Overlie foi publicado ${ }^{23}$, essa sensação torna-se mais evidente.
\end{abstract}

\footnotetext{
22 Solicitei ao Barney que clarificasse a sua participação efetiva numa companhia ou projeto artístico dirigido por Mary Overly. Respondeu da seguinte forma: na realidade nunca efetivamente participei num projeto dirigido pela Mary. Há três anos atrás [2019] ela convidou-me para atuar na "Celebration for Mary Overlie at Danspace”, na St. Mark's Church, surgiu uma situação de conflito e por isso acabei por não participar.

${ }^{23}$ Quarto trimestre de 2016.
} 
Não posso senão estar de acordo contigo.

No início do Conservatory, por exemplo, trabalhávamos a partir de nove Viewpoints, mas, a determinado momento do percurso - e que, do meu ponto de vista, coincide mais ou menos com a publicação do livro de Overlie e com a vinda de Wendell para orientar uma semana de trabalho enquanto artista convidado -, passámos a ouvir falar com muito mais ênfase de seis Viewpoints e do trabalho de Mary Overlie, nomeadamente nas tuas sessões. Poderei ainda acrescentar que tenho a sensação de que essa mudança aconteceu também numa altura em que, nas sessões de improvisação a partir dos Viewpoints (todas as manhãs), se sentiam igualmente zonas de repetição, pois os mesmos mecanismos surgiam entre os participantes. Sentia-se que faltava mais alguma coisa nesse trabalho, como se as sessões fossem um pouco 'estéreis'. O que aqui partilho tem, em ti, algum eco?

Antes de mais, quero clarificar que a Mary Overlie, ao longo do seu percurso, fez variadíssimas tentativas de sistematizar a sua abordagem por via da escrita. Existiram, portanto, várias versões desse livro, que só agora, passados tantos anos, foi finalmente editado. Acrescento, depois, que estou consciente de que existe muita gente que desenvolve exercícios de viewpoints pensando que foram criados pela Anne...

Depois de algum tempo a trabalhar convosco, começou a ser possível destrinçar modos de abordagem diferenciados de cada um dos membros da SITI, por exemplo, quando ensinam os Viewpoints ou Suzuki. O que pode caracterizar a tua forma de abordar os Viewpoints, relativamente à dos teus colegas?

A minha abordagem está claramente mais próxima do trabalho desenvolvido por Mary Overlie. A sua abordagem leva-nos sempre a colocar questões de base: o que é que este trabalho mobiliza? Do que se trata, verdadeiramente? Devemos sempre voltar a colocar estas questões de base para descobrir novos caminhos, e sempre existirão variadíssimas respostas, em vez de uma só. Deverá ser um contínuo questionamento.

Com os teus colegas discutem-se as diferenças que existem entre vós, e de forma aberta? 
Tenho a sensação de que, ao longo dos anos, fomos acumulando experiências e cumplicidades que nos levaram a construir canais de comunicação e que agora nos permitem estabelecer, entre nós, discussões francas, abertas e produtivas.

Se procurasse caracterizar as especificidades da tua abordagem, diria, por exemplo, que é notória a tua influência das técnicas 'somato-corporais' ou 'release techniques', onde a consciência sensitiva e percetiva da ação entra mais em jogo. De novo, o que dirias tu?

O meu trabalho é claramente mais centrado sobre o movimento e a fisicalidade e encontra-se, portanto, mais próximo dos Viewpoints. No seio da companhia esse será mais o meu território e onde poderei melhor dar o meu contributo. E isso também tem a ver com a minha própria história, a minha herança, e que é diferente da dos outros colegas. Esse é um elemento que, do meu ponto de vista, enriquece o trabalho da SITI. Eu, por exemplo, venho mais do domínio da dança, da dança-teatro e das práticas somáticas.

Para entrar mais nos detalhes, partilho ainda contigo uma reflexão que tenho desenvolvido durante estes meses de prática, tanto da técnica Suzuki como dos Viewpoints. Entre as duas abordagens parecem-me existir conceções de corpo e conceções do ensino e aprendizagem bem diferentes; talvez possa mesmo dizer que os seus fundamentos se situam em direções diametralmente opostas. Por exemplo, o Suzuki propõe uma aprendizagem assumidamente por via da forma corporal. Nas sessões há sempre um rigor formal muito grande e que demanda uma enorme concentração e intensidade energética, enquanto que nas sessões de Viewpoints o que mais se mobiliza é um jogo e é uma tomada de consciência dos mecanismos da perceção: separam-se artificialmente parâmetros de base do acting para depois podermos, conscientemente, priorizar a nossa atenção neste ou naquele. $\mathrm{O}$ jogo criativo, neste contexto, que surge a partir de uma escuta dos fenómenos cénicos, constrói-se de uma exploração de diferentes pontos de vista sobre esses mesmos fenómenos. O Suzuki demanda também, por seu lado, uma atitude mais voluntária e mais controlada da tua decisão de ação, enquanto que os Viewpoints colocam em jogo muito mais uma escuta e um diálogo com tudo aquilo que está a acontecer, num determinado momento, à nossa volta. Como se, em termos processuais, o mais ajustado fosse deixares-te surpreender pelos estímulos que recebes, e será desse modo que melhor poderás construir o teu jogo a partir do que te advém.

Enfim, entre estas duas abordagens parece-me existir como que um 
paradoxo, um certo conflito, diria mesmo. O que pensas sobre isto? E como é que, pessoalmente, dialogas com estes dois 'universos' e com estes dois modos de proceder?

Quando estou a praticar ou a ensinar Suzuki procuro que a minha abordagem e os meus comentários deem maior ênfase aos aspetos sensitivos e somáticos. E procuro olhar para o Suzuki a partir dessas dimensões, e que são as minhas referências. Por outro lado, a mobilização do imaginário não é uma dimensão que se deva descartar no Suzuki, diria mesmo que é uma parte importante e substancial desse trabalho e que nos aproxima do trabalho do acting.

Para melhor me situar: ajuda-me referir que o Suzuki segue estratégia idêntica à que a dança 'clássica' usa em termos de aprendizagem, enquanto a grande referência dos Viewpoints, o modo como se pensa e como se age, é o pósmodernismo. De qualquer maneira, penso sinceramente que as duas abordagens são muito complementares, apesar de serem totalmente diferentes. E eu gosto desse 'conflito', tem sido para mim muito útil.

Percebo, e começo a descobrir, justamente, que é a mim que compete encontrar o diálogo e a interceção, o bom balanço entre essas duas abordagens. É importante saber ajustar a atitude ao que demanda cada uma dessas abordagens, ou seja, os enfoques e os desafios devem ser diferentes quando vou para uma sessão de Suzuki ou quando vou para uma de viewpoints. Com o aprofundar da prática, pressinto até que poderia vir a encontrar como que uma atitude comum construída a partir dessas duas 'polaridades'. E isto tanto no modo como abordo a prática, propriamente dita, como também no modo diferenciado como essas duas abordagens (Suzuki e Viewpoints) concebem a cena e o trabalho do acting.

E eu acrescentaria que a atitude dependerá também da forma como te encontras cada dia, ou cada semana.

\section{O que, de concreto, a prática de Suzuki te tem oferecido?}

Quando comecei a treinar, odiava Suzuki. Nas sessões só pensava em ir-me embora para poder estar a fazer uma outra coisa qualquer, de tal forma esse trabalho era exigente e difícil para mim. Mas, ultrapassada essa etapa, ao dar 
continuidade ao trabalho, comecei a sentir que o Suzuki me dava uma espécie de 'eixo' e de 'organização da expressão', competências que me faltavam. Aos poucos, comecei a descobrir essas partes de mim que estavam como que adormecidas e que a imagem que tinha formado de mim próprio também não integrava. Assim, comecei a sentir que poderia também construir uma presença cénica mais concentrada e forte, uma presença com um 'tom' mais heroico. Antes de praticar Suzuki eu não tinha, ou não conhecia, em mim essas qualidades. E essas competências possibilitam-te abordar personagens 'clássicas' e que têm essa carga dramática.

\section{E onde a imobilidade predomina...?}

Efetivamente. A formação habitual do ator americano estimula a realização de muitos gestos, gesticula-se muito! O Suzuki, por seu turno, permite-nos pensar a imobilidade como referência para a atuação. Por outro lado, ainda, o acting americano constrói-se muito pela análise do comportamento das personagens e o que o Suzuki propõe, ao contrário, é: constrói uma imobilidade forte e potente e será a partir daí que a tua palavra nasce. Não será necessário muito mais! É toda uma outra forma de conceber e pensar o trabalho do acting, um modo muito menos 'psicológico'.

\section{Poderia evocar um dos parâmetros que caracteriza a dança pós-moderna americana referindo que a imobilidade a que fazes alusão é bem diferente do conceito de free-flow, por exemplo, explorado por Trisha Brown²4.}

A combinação entre Suzuki e Viewpoints leva-te a encontrares um ponto de equilíbrio entre a linha vertical e a linha horizontal da tua presença.

24 Trisha Brown, uma das artistas Americana mais destacadas do movimento da dança pós-moderna americana. O seu percurso carateriza-se por um questionamento sobre os fundamentos do que até aí se considerável fazer parte do repertório da dança, criando novos vocabulários e metodologias de composição. A Trisha Brown Dance Company criada em 1970 é uma referência incontornável no universo da dança e da performance das últimas décadas. Mais informações podem ser encontradas em: https://trishabrowncompany.org/ 
Se treinarmos com a mesma técnica durante anos e de forma regular, os objetivos e os desafios forçosamente alteram-se. Desde logo, porque te tornas mais velho e o corpo não responde do mesmo modo. Como é que tu verbalizas as mudanças que se têm operado em ti ao longo do tempo?

Tenho agora 51 anos [2017] e hoje confronto-me com uma lesão crónica nas costas. Só por isso, a minha forma de abordagem terá de ser forçosamente diferente daquela que tinha quando tinha 24 anos, particularmente com a técnica Suzuki. Sem deixar de fazer os katas, as posições corporais e os diferentes exercícios, sou, portanto, obrigado a encontrar modos mais 'económicos' de realizar as ações, com muito mais atenção à sensação e à prevenção de possíveis lesões. Todas estas estratégias põem em jogo uma outra 'inteligência corporal' e que implica uma outra maturidade.

As atitudes corporais e as ações que fazem parte do repertório da técnica Suzuki são para mim, de algum modo, antinaturais. E, sendo mal executadas, podem muito rapidamente criar lesões no corpo.

É verdade, mas muitos outros movimentos podem criar lesões no corpo, basta um movimento mal feito numa improvisação e uma lesão pode muito bem surgir. Ficando mais velho, acho que a minha escuta sensitiva se tem tornado mais fina e subtil, e isso ajuda também a prever as lesões.

\footnotetext{
Se fizermos um transfer para a área da pedagogia, pergunto-te se sentes que a escuta sensitiva que referes enquanto performer se repercute também no modo como, enquanto pedagogo, orientas as sessões de grupo. Achas que essa outra qualidade de escuta te permite, por exemplo, perceber melhor o que determinado grupo necessita e/ou demanda a determinado momento? Poderei dizer que este nosso grupo do Conservatory sente que a tua escuta afinada tem aberto espaço para que o grupo possa entrar numa zona mais sensitiva aquando das improvisações. Tu tens sabido ajustar aquilo que tinhas planeado para a sessão de acordo com a tua leitura do 'estado' e das respostas que o grupo vai dando aos exercícios propostos.
}

Fico contente com essa vossa sensação. Do meu ponto de vista, sinto que uma escuta mais refinada me ajuda, efetivamente, a melhor conduzir as sessões. E até com menos esforço! 
A SITI demanda aos seus performers que se 'movimentem' também no âmbito da pedagogia. De que modo é que a pedagogia 'alimenta' o teu trabalho enquanto performer? E de que modo é que o pode limitar?

Não fazia parte dos meus planos iniciais ser professor, mas esse papel foi-se impondo de forma natural. Tenho muitas inspirações artísticas que surgem da minha ação pedagógica. E, se não fosse assim, não continuaria a fazê-lo.

\section{Em que sentido é que o teu trabalho pedagógico alimenta o teu trabalho} artístico?

Quando desenho as sessões, imagino situações no âmbito da criação e, assim, a minha criatividade é ativada, desafiada, e não se cristaliza. Mas ensinar durante muito tempo consecutivo faz-me sentir fora do universo da criação.

\section{A pedagogia necessita, portanto, da criação para ser 'recarregada'?}

Exato. É tudo uma questão de equilíbrio. O facto de trabalhar com outros artistas fora da companhia também é muito importante para a minha vitalidade artística. É importante estar e experimentar com outras pessoas. E eu tenho necessidade de trabalhar com outros artistas que não têm a minha linguagem, até para me aperceber melhor do que penso e do que faço.

\section{Referiste anteriormente que, no seio da companhia, tu serás aquele que está mais 'talhado' para desenvolver o trabalho no âmbito do movimento e da improvisação. Mas isso também não pode ser uma limitação, ou seja, uma 'etiqueta' que te limita e que te impossibilita de desenvolver outras áreas no seio do grupo?}

Estou sempre a tentar combater um qualquer papel ou algum tipo de especialização que possa vir a constranger o meu percurso. É por isso, também, que continuo a aceitar trabalhar enquanto artista fora da companhia. Este ano, por exemplo, já desenvolvi mais do que um projeto enquanto coreógrafo. De ano para ano, a situação muda. Por vezes estou mais no palco, outras mais no papel da 
encenação ou mesmo no da pedagogia.

Falando em pedagogia, gostaria agora de te ouvir falar de forma mais específica sobre o Conservatory. Quão importante é, para a SITI, organizá-lo?

Antes de decidirmos realizar o Conservatory trabalhámos com muitas pessoas. Fizemos muitas, mas mesmo muitas formações de duas a três semanas, e mesmo workshops de menor duração. Sentimos, a determinado momento, que seria importante experimentar outra coisa, como, por exemplo, seguir um grupo por um período mais longo, de modo a ser possível constatar como é que a nossa ação se inscreve e pode mudar as pessoas de forma mais aprofundada e permanente. E, simultaneamente, como é que esse encontro poderia mudar-nos a nós próprios, tanto a nível das nossas relações como enquanto pedagogos. Acreditámos que esse tempo mais continuado em conjunto permitir-nos-ia levantar outras questões e levar-nos-ia a encontrar outras respostas, através da experimentação prática. Enfim, seguir um grupo durante mais tempo permite aprofundar o trabalho que desenvolvemos.

Quais as aprendizagens que te parecem ter sido das mais marcantes depois destes três programas de Conservatory?

Assim de repente, diria que temos de prestar atenção à carga de trabalho que propomos. O 'muito' será, talvez, 'demasiado'. Encontrar a justa medida sem perder o rigor e a intensidade é um dos desafios que temos de aprender a gerir. Em que momentos é mais eficaz criar algumas pausas no trabalho é outra das questões a tratar. E isto tanto para os estudantes como para nós próprios. Na nossa idade, trabalhar fisicamente todos os dias e com uma intensidade considerável é exigente. Para além do mais, durante o programa de Conservatory, que dura cerca de oito meses, nós não interrompemos o trabalho criativo da companhia. É certo que fazemos menos criações durante esse período, mas continuamos a trabalhar. Em suma, aprender a desenhar e a gerir todas essas dimensões é um dos desafios que temos nesta fase do percurso da SITI.

Poderei ainda acrescentar que, em cada Conservatory aprendi coisas bem 
distintas, porque os grupos foram, também eles, completamente diferentes. Enfim, por vezes é difícil saber verbalizar as aprendizagens que uma prática nos está a trazer, mas poderei dizer que, com o teu grupo, foi possível ir mais em profundidade no trabalho e, ao mesmo tempo, desenvolver uma experimentação mais aberta, quer dizer, entrar em zonas que não dominamos, mas que nos interessa investigar. Este grupo, muito mais do que os outros, permitiu-me esse tipo de trabalho, e isso foi para mim muito estimulante. E, quando isso acontece, é muito rico e prazeroso.

Gostaria de partilhar contigo, e uma vez mais, o que fui sentindo. No início das tuas sessões senti-te muito à procura de qual a melhor direção a dar ao trabalho. Mas o facto de a teres encontrado muito rapidamente fez com que entre nós se criasse um clima de confiança. E na pedagogia essa dimensão parece-me fundamental, para podermos depois arriscar noutras zonas de experimentação e, ao mesmo tempo, desenvolver com mais precisão aquilo em que acreditamos e que procuramos na nossa visão do trabalho.

Vocês deram-me permissão para poder explorar aquilo que intuo e procuro.

\begin{abstract}
Durante o Conservatory, os diferentes membros da SITI participam na sessão que os outros dirigem, e isso permite-vos conhecer melhor o 'estado' em que cada um se encontra, as questões que cada um se coloca num dado momento. Ter esse espaço poderá ser muito enriquecedor, pois permitirá também como que 'tomar o pulso' da SITI através de um sentir das diferenças de cada um a determinado momento do seu percurso. O que poderás tu dizer sobre isto?
\end{abstract}

Penso que esse tipo de reflexão, o poder comparar-se com um outro, ou o poder aprender através do olhar do outro, acontece quando existe um grupo coeso que trabalha em conjunto há algum tempo.

Gostaria de saber o teu ponto de vista sobre a articulação entre aprendizagens técnicas e aprendizagens mais do domínio da criação e da composição cénica. Como é que pensas essa articulação no universo artístico, e de forma geral, e como, em particular, a consideras no âmbito do SITI Conservatory?

Partilho, desde já, que para mim o trabalho técnico que propuseram ao longo do programa foi muito mais transformador do que o trabalho de criação artística propriamente dito. Para além do mais, senti ainda que a articulação 
entre estas duas dimensões foi um dos aspetos que menos evidentes.

Penso que essa articulação que referes é, efetivamente, uma das questões essenciais e que nunca está completamente resolvida. Eu acho até que é uma das questões que não têm uma resposta definitiva. De mim para mim, não consigo respondê-la de forma clara e definitiva. Mas se me fizerem a pergunta a mim, individualmente, eu responderia que, por um lado, treino e, por outro, ensaio, e que no fundo são duas coisas mais ou menos diferentes ou separadas uma da outra. Em certo sentido, o treino permite-me entrar na sala de trabalho para os ensaios e sentir-me mais aberto para qualquer coisa que possa acontecer. E um grupo que treina em conjunto será mais capaz de, em conjunto, seguir o caminho que a imprevisibilidade the apresentar. Treinar desenvolve a capacidade e a sensação de estar pronto.

\begin{abstract}
Os Viewpoints, entendidos como treino do performer, desenvolvem justamente essa capacidade de adaptação ao instante, de flexibilidade e de sermos capazes de mudar de ponto de vista muito rapidamente. Mas operar com os Viewpoints pode, igualmente, levar-nos a 'levantar' material para a criação.
\end{abstract}

Sim, sim, e para a capacidade de colocar as cenas no espaço [staging].

Mas durante o Conservatory pareceu-me que os Viewpoints foram mais utilizados como treino. Criou-se um vocabulário conjunto, é certo - que será também uma das importantes valências que se produzem com os Viewpoints -, mas depois, no campo da composição, o grupo não aplicava ou não usava esse mesmo vocabulário. E isso gerou uma série de conflitos e de falta de articulação entre as partes.

Estou de acordo contigo. Essa interligação deveria ter sido mais trabalhada e desenvolvida. Esse tipo de passagem é o que mais me interessa e penso que os parâmetros sinalizados pelos Viewpoints podem muito bem servir de abordagem para desenvolver um projeto de criação. Na minha vida de artista, quer como performer quer como coreógrafo, aplico os Viewpoints nessas várias dimensões do trabalho criativo. 


\section{E, para terminar, pergunto-te: no momento atual, qual é o teu enfoque?}

Estou interessado em perceber o que se passa nos meus processos interiores durante as fases de criação-investigação, ou seja, o que me leva a realizar determinada ação. E como é que eu próprio observo ou tenho consciência dos meus mecanismos de decisão no próprio momento em que estou a atuar, quer seja em cena ou no campo da pedagogia.

\section{Obrigado, Barney.}

\section{Quais são os novos desafios da SITI-Company e do SITI-Conservatory?}

A SITI ainda tem o seu escritório em Midtown mas alugou o seu estúdio de trabalho. Estamos no processo de produzir a nova temporada que será a final. É por isso que pode não haver mais nenhuma edição do SITI Conservatory. Mas ainda nada está definido.

\section{Mary deixou-nos à cerca de um ano atrás. Sentes que também a ti compete a missão de dar continuidade ao seu trabalho e contribuir para que o seu nome não seja esquecido no contexto dos Viewpoints?}

Absolutamente! O trabalho e a contribuição de Mary para as artes performativas são enormes e devem ser continuados e lembrados. Os seus discípulos mais recentes e jovens iniciaram o projeto Mary Overlie Legacy ${ }^{25}$. sixviewpoints.com.

\section{Referencias}

OVERLY, MARY. Standing in Space. The six Viwpoints Theory \& Pratice. Montana.

${ }^{25}$ Mais informações podem ser encontradas em: www.sixviewpoints.com. 
Fallon Presse, 2016

PORTEIRO, Tiago. Um pedagogo em viagem. SITI-Conservatory - Formação e intercâmbio artístico em artes cénicas. Educar em Revista, v. 34, n. 67, p. 21-37, 2018. Disponível em: https://revistas.ufpr.br/educar/article/view/56083

Recebido em: 15/08/2021

Aprovado em: 30/09/2021 